\title{
To compare the perinatal outcome of IUGR infants with abnormal and normal antenatal umbilical artery Doppler flow in the immediate neonatal period
}

\author{
Shivaprasad B. ${ }^{1 *}$, Devendrakumar Sharma ${ }^{2}$
}

${ }^{1}$ Department of Neonatology Department, ${ }^{2}$ DNB Pediatric Trainee, St. Martha’s Hospital, Bengaluru, Karnataka, India

Received: 23 January 2017

Revised: 28 January 2017

Accepted: 02 March 2017

\section{*Correspondence:}

Dr. Shivaprasad B.,

E-mail: neoprasad@gmail.com

Copyright: (C) the author(s), publisher and licensee Medip Academy. This is an open-access article distributed under the terms of the Creative Commons Attribution Non-Commercial License, which permits unrestricted non-commercial use, distribution, and reproduction in any medium, provided the original work is properly cited.

\section{ABSTRACT}

Background: Intrauterine growth restriction (IUGR) is one of the cause of perinatal mortality and morbidity and affects approximately $7-15 \%$ of worldwide pregnancies. IUGR is the failure of the fetus to achieve intrinsic growth potential, due to disorders and diseases in the feto-placental-maternal unit. Doppler indices from the fetal circulation can reliably predict adverse perinatal outcome. Aim of the study was to determine perinatal outcome of IUGR infants with abnormal antenatal umbilical artery Doppler flow versus IUGR infants with normal Doppler flow.

Methods: All Preterm and term IUGR infants with abnormal and normal antenatal umbilical artery Doppler scan admitted in NICU of St Martha's Hospital were included in the study. 30 in each group with total sample size of 60. Study was conducted from March 2015 to February 2016. Primary outcome measure will be neonatal mortality and secondary outcome measure will be neonatal morbidities like perinatal asphyxia, hypoglycemia, NEC, polycythemia, sepsis, hyperbilirubinemia etc.

Results: IUGR infants with abnormal antenatal umbilical artery Doppler scan were included as cases and those with normal antenatal umbilical artery Doppler scan as control. At birth resuscitation rate and therefore perinatal asphyxia was observed more in case group, 11 out of 30 (36.6\%), compared to 1 out of $30(3.3 \%)$ in control group, statistically significant $(\mathrm{P}<0.05)$. Hypoglycemia was noticed in 19 infants in case group $(63.3 \%)$ compared to 2 infants $(6.6 \%)$ in control group, statistically significant. NEC, polycythemia, sepsis was noticed more in case group, but statistically not significant.

Conclusions: Infants with abnormal antenatal Doppler flow are at increased risk of perinatal complications than infants with normal antenatal umbilical artery Doppler and needs extra care during this period.

Keywords: Antenatal Doppler flow, IUGR, Neonatal outcome

\section{INTRODUCTION}

Intrauterine growth restriction (IUGR) is one of the most important causes of perinatal mortality and morbidity and affects approximately $7-15 \%$ of worldwide pregnancies. ${ }^{1}$ IUGR and SGA both the terms are inter changeably and both denote malnutrition, there is a minor difference in terminology. SGA is a statistical definition, is used for neonates whose birth weight is less than $10^{\text {th }}$ centile for that particular gestational age population norms. Intrauterine growth restriction (IUGR) is defined as fetal growth less than the normal growth potential of a specific infant because of genetic or environmental factors. IUGR is a clinical definition and applied to neonates with clinical evidences of malnutrition. ${ }^{2}$ Many preterm infants are also IUGR when growth is based on fetal growth standard. IUGR preterm infants are at increased risk for perinatal death and neonatal complications. ${ }^{3}$ 
Intrauterine growth restriction (IUGR) is the failure of the fetus to achieve his/her intrinsic growth potential, due to anatomical and/or functional disorders and diseases in the feto-placental-maternal unit. $^{4}$ Worldwide, IUGR is observed in about $24 \%$ of newborns; approximately 30 million infants suffer from IUGR every year. ${ }^{5,6}$ The burden of IUGR is concentrated mainly in Asia which accounts for nearly $75 \%$ of all affected infants. Africa and Latin America account for $20 \%$ and $5 \%$ cases respectively. National Neonatal Perinatal Database of India reported the incidence of IUGR to be $9.65 \%$ among hospital born live birth infants. ${ }^{7}$

Normal intrauterine growth occurs in three stages. The first stage takes place during 4-20 weeks of gestation, rapid cell division and multiplication (hyperplasia) occurs as the embryo grows into a fetus. The second stage, 20-28 weeks of gestation, cell division declines and the cells increase in size. The third stage, $28-40$ weeks, there is rapid increase in cell size, rapid accumulation of fat, muscle, and connective tissue. Most fetal weight gain occurs during the last 20 weeks of gestation. If during this delicate time of development and weight gain, is disturbed or interrupted, the baby can suffer from IUGR. ${ }^{8}$

The etiology of IUGR can be divided into three categories: maternal, fetal, and placental. Among the maternal ones all medical conditions affecting the microcirculation that cause fetal hypoxemia, vasoconstriction or a reduction in fetal perfusion like hypertension, typically in preeclampsia as well as severe chronic diseases like renal insufficiency, SLE, chronic anemia or gestational diabetes.

Other principal reasons are the behavioral conditions including substance abuse, (alcohol or heroin) or smoking. Fetal causes of IUGR are congenital anomalies, intra uterine infections, exposure to teratogens. The most common causes of SGA in non-anomalous fetus is impaired placental perfusion, placenta previa is one of the well recognized pathology determining IUGR, other rare conditions are mosaicism, chorioangioma, infarcts or partial abruptions. ${ }^{9}$

The introduction of color Doppler technology has provided the first opportunity for repetitive noninvasive hemodynamic monitoring in pregnancy. There is ample evidence that Doppler indices from the fetal circulation can reliably predict adverse perinatal outcome in an intrauterine growth restricted (IUGR) pregnancy. Compared to other methods of fetal monitoring, Doppler has proved to be more sensitive in detecting fetal compromise early and aids in the guiding and making of decisions regarding the appropriate timing of delivery. ${ }^{10}$

If adequate measures are not taken at this point, venous changes appear in the severely compromised fetus. These are strong predictors of poor perinatal outcome and indicate impending irreversible damage. Doppler reveals changes of hypoxia at least a week before the non-stress test or the biophysical profile. It has therefore become the gold standard in the management of the growth-restricted fetus. ${ }^{11,12}$

Since IUGR neonates are more likely to suffer complications including Perinatal Asphyxia, Cold stress, Hypoglycemia, Hypocalcaemia, Hyperbilirubinemia, Feed intolerance, NEC, Sepsis and even mortality. It is important that these infants are identified and managed appropriately at birth. Even after recovering from neonatal complications, they remain more prone to poor physical growth, poor neurodevelopment outcome, recurrent infections and chronic diseases (hypertension, hyperlipidemia, coronary artery disease) later in life. ${ }^{13,14}$

Main purpose of this study is to compare the acute complications of IUGR infants with abnormal and normal antenatal umbilical artery Doppler scan. The aim was to determine perinatal outcome of IUGR infants with abnormal antenatal umbilical artery Doppler flow versus IUGR infants with normal Doppler flow.

\section{METHODS}

All Preterm and term IUGR infants with abnormal and normal antenatal umbilical artery Doppler scan admitted in NICU of Paediatric department in St Martha's Hospital. Inpatient IUGR infants in NICU of Paediatric department in St Martha's Hospital were studied. An observational, comparative, cohort study was done on 30 in each group with total sample size of 60 . Study was conducted for duration of 12 months from March 2015 to February 2016.

Absent end diastolic flow, reversed end diastolic blood flow and High resistance flow in umbilical artery on antenatal Doppler scan is defined as abnormal. Primary outcome measure will be neonatal mortality. Secondary outcome measure will be neonatal morbidities like Perinatal asphyxia, Hypoglycemia, Feed intolerance, NEC, Polycythemia, Sepsis, Hyperbilirubinemia etc.

\section{Inclusion criteria}

- Preterm and term infants with IUGR with abnormal antenatal Doppler scan

- Preterm and term infants with IUGR with normal antenatal Doppler scan

\section{Exclusion criteria}

- IUGR infants without antenatal umbilical artery Doppler scan

- IUGR infants with major congenital anomaly

At the time of birth of preterm or term IUGR infants, diagnosis was made according to CAN score within 48 hours of birth. Before starting the study, inter and Intra observer variations of the CAN score were tested and found to be within acceptable limits ( $p>0.05$ ). After diagnosis of IUGR infants, antenatal data regarding umbilical artery Doppler scan of mother was followed up 
and infants with abnormal umbilical artery Doppler flow i.e. absent, reversed blood flow or high resistance flow in umbilical artery on antenatal Doppler scan were included in the study as a case and IUGR infants with normal umbilical artery Doppler flow were included as control, after taking informed consent from the parents.

IUGR infants without antenatal umbilical artery Doppler scan, with congenital anomalies and IUGR infants born as a result of multiple gestations were excluded from the study. CAN score was used for diagnosis of IUGR infants clinically. It includes 9 parameters namely hair, cheeks, neck and chin, arms, legs, back, buttocks, chest and abdomen. Each neonate was graded according to their physical appearance; total sum of all physical characteristics was concluded as CAN score. A neonate with CAN score of less than 25 was considered malnourished or IUGR and included in the study.

IUGR infants admitted to NICU were followed up for perinatal complications like perinatal asphyxia, hypoglycemia, polycythemia, feed intolerance, necrotizing enterocolitis (NEC), sepsis and hyperbilirubinemia. Continuous variables were reported using mean $\pm \mathrm{SD}$ (standard deviation) for the normally distributed variables otherwise median and inter-quartile range was used. Categorical variable were reported using number and percentages. Chi-square/Fisher's exact test used to find the association between various complications, term babies with Doppler group. Independent $t$ test was used to compare the differences between the two Doppler group with CAN score.

\section{Statistical analysis}

Correlation was used to find the relationship between the can score and number of hospital stays. Logistic regression used to predict the Doppler group from various complications. All the analysis was done using SPSS version 23.0. All the analysis was statistical significant at $5 \%$ level ( $\mathrm{p}$ value $<0.05$ ).

\section{RESULTS}

The study compares the perinatal outcome of IUGR infants with normal and abnormal antenatal umbilical artery Doppler flow. Total 60 IUGR infants were studied with 30 infants in each group. IUGR infants with abnormal antenatal umbilical artery Doppler scan were included as cases and IUGR infants with normal antenatal umbilical artery Doppler scan were included as control.

In our study, in normal Doppler scan group, out of 30 IUGR infants $13(43.3 \%)$ were male and 17 (56.7\%) were female. In abnormal Doppler scan group, out of 30 IUGR infants $16(53.3 \%)$ were male and $14(46.7 \%)$ were female. Out of total 60 IUGR infants, $29(48.33 \%)$ were male and $31(51.66 \%)$ were female. It suggests both male and female infants are almost similarly predisposed for IUGR in both group.

In our study mean weight, length, Head circumference, Chest circumference and CAN score were lower of IUGR infants with abnormal Doppler group compared to normal group.

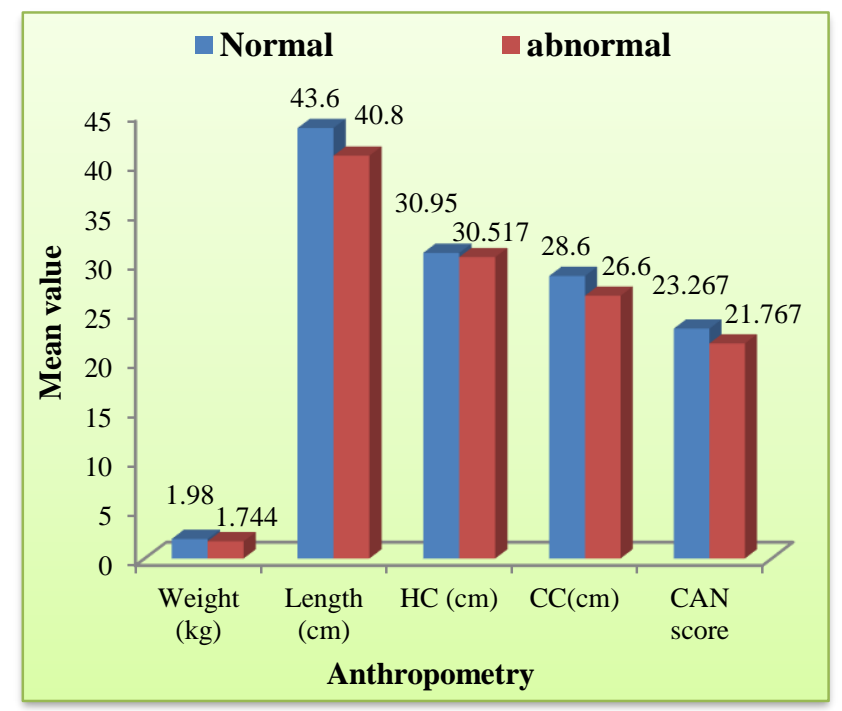

Figure 1: Comparison of anthropometry and CAN score.

Number of primigravida mother who delivered IUGR infants were $13(43.3 \%)$ in control group compared to 14 $(46.7 \%)$ in case group. Mean gestation age of IUGR infants at birth was $36+3$ weeks in control group while in case group it was $35+5$ weeks. It is suggestive of that infants with abnormal antenatal umbilical artery Doppler scan were born more premature than infants with normal antenatal umbilical artery Doppler scan. This association was not statistically significant.

Although LSCS rate was more in abnormal Doppler scan group, 19 out of $30(63.3 \%)$ compared with normal group 13 out of $30(43.3 \%)$. It was not statistically significant. (P value $<0.05)$. No mortality was observed in either of group. At birth resuscitation rate and therefore perinatal asphyxia was observed more in case group, 11 out of 30 (36.6\%), compared to 1 out of $30(3.3 \%)$ in control group. It was statistically significant $(\mathrm{P}$ value <0.05). Hypoglycemia was noticed in 19 infants in case group (63.3\%) compared to 2 infants $(6.6 \%)$ in control group. This association was statistically significant. ( $\mathrm{P}$ value < $0.05)$. NEC was noticed in 3 infants $(10 \%)$ in case group compared to 1 infant $(3.3 \%)$ in normal group but this association was not statistically significant. Feed intolerance rate was $30 \%$ (9 infants out of 30) in case group and $13.3 \%$ (4 infants out of 30 infants). Although feed intolerance with gastric aspirates $>50 \%$ of previous feed was noticed more in case group, this association was not statistically significant. 
Table 1: Perinatal complications (univariate analysis).

\begin{tabular}{|c|c|c|c|c|}
\hline Complications & & Normal Doppler N (\%) & Abnormal Doppler N (\%) & p-value \\
\hline \multirow[b]{2}{*}{ Asphyxia } & Yes & $1(8.3)$ & $11(91.7)$ & \multirow[b]{2}{*}{$0.002^{*}$} \\
\hline & No & $29(60.4)$ & $19(39.6)$ & \\
\hline \multirow{2}{*}{ Hypoglycemia } & Yes & $2(9.5)$ & $19(90.5)$ & \multirow{2}{*}{$<0.001^{*}$} \\
\hline & No & $28(71.8)$ & $11(28.2)$ & \\
\hline \multirow{2}{*}{ Polycythemia } & Yes & $01(25)$ & $03(75)$ & \multirow{2}{*}{0.61} \\
\hline & No & $29(51.8)$ & $27(48.2)$ & \\
\hline \multirow{2}{*}{ NEC } & Yes & $01(25)$ & $03(75)$ & \multirow{2}{*}{0.61} \\
\hline & No & $29(51.8)$ & $27(48.2)$ & \\
\hline \multirow{2}{*}{ Feed intolerance } & Yes & $04(30.8)$ & $09(69.2)$ & \multirow{2}{*}{0.21} \\
\hline & No & $26(55.3)$ & $21(44.7)$ & \\
\hline \multirow{2}{*}{ Sepsis } & Yes & $07(31.8)$ & $15(68.2)$ & \multirow{2}{*}{$0.032^{*}$} \\
\hline & No & $23(63.5)$ & $15(39.5)$ & \\
\hline \multirow{2}{*}{ Hyperbilirubinemia } & Yes & $13(54.2)$ & $11(45.8)$ & \multirow{2}{*}{0.598} \\
\hline & No & $17(47.2)$ & $19(52.8)$ & \\
\hline Duration of hospital stay (Days) & & $6(5,8)$ & $08(6,26)$ & $0.003 *$ \\
\hline
\end{tabular}

\#Value reported by median (1st Quartile, 3rd Quartile), p value from Mann-Whitney U test. *p-value statistically significant at $5 \%$ level.

Similarly polycythemia was noticed more in case group, 3 (10\%) infants compared to 1 (3.3\%) infant in control group, but this association was not statistically significant. Sepsis rate with positive sepsis screen and requirement of 2nd or 3rd line antibiotics was observed more in case group. Out of 30 infants $10(33.3 \%)$ were considered as having sepsis compared to $6(20 \%)$ in control group. This association was statistically not significant. Hyperbilirubinemia was found more in control group compared to cases. Out of 30 infants $13(43.3 \%)$ had Hyperbilirubinemia in control group while total 11 (36.6\%) infants had Hyperbilirubinemia in case group. This can be attributed to more premature infants had Hyperbilirubinemia in control group than in case group.

Duration of hospital stay was observed more in case group with mean duration of stay noticed was 8 days with 1st and 3rd quartile range of 6 and 26 days respectively. In control group mean duration of hospital stay was 6 days with 1 st and 3rd quartile range of 5 and 8 days respectively. This association was statistically significant suggestive of IUGR infants with abnormal antenatal Doppler scan stays longer in NICU compared with IUGR infants with normal antenatal Doppler scan.

In our study IUGR infants with abnormal Doppler were observed to have more chances of having more than one complication during perinatal period compared to IUGR infants with normal Doppler. This association was statistically significant and suggests IUGR infants with abnormal Doppler are more prone to have more than one complication during perinatal period compared to IUGR infants with normal Doppler.

In case group $18(60 \%)$ infants were born pre term $(<37$ completed gestation week) with mean gestation age of $35+5$ weeks compared to $16(53.3 \%)$ infants in control group with mean gestation age of $36+3$ weeks. It suggests, in our study abnormal antenatal Doppler scan was associated with increased preterm birth but this association was not statistically significant.

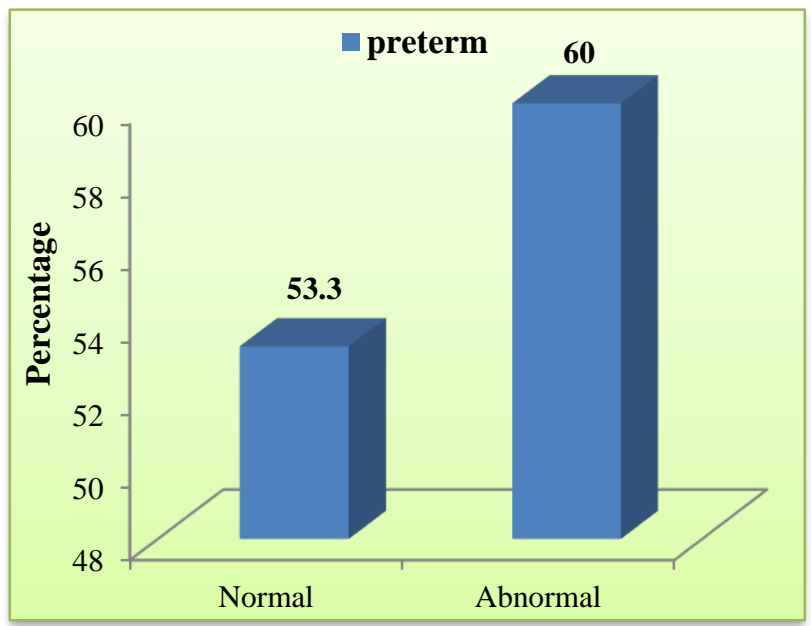

Figure 2: Risk of prematurity in both groups.

Infants having hypoglycemia $(\mathrm{aOR}=27.32, \mathrm{p}<0.000)$ are more likely to being in an abnormal Doppler group which was statistically significant. Infants having perinatal asphyxia, sepsis and prolonged duration of hospital stay are also more likely to being in abnormal Doppler group but this association was not statistically significant in our study.

In our study mean CAN score was lower in IUGR infants with abnormal Doppler group compared to normal group. Lower CAN score was associated with more complications and increased duration of hospital stay. This association was statistically significant. ( $\mathrm{P}$ value $<0.05)$. 


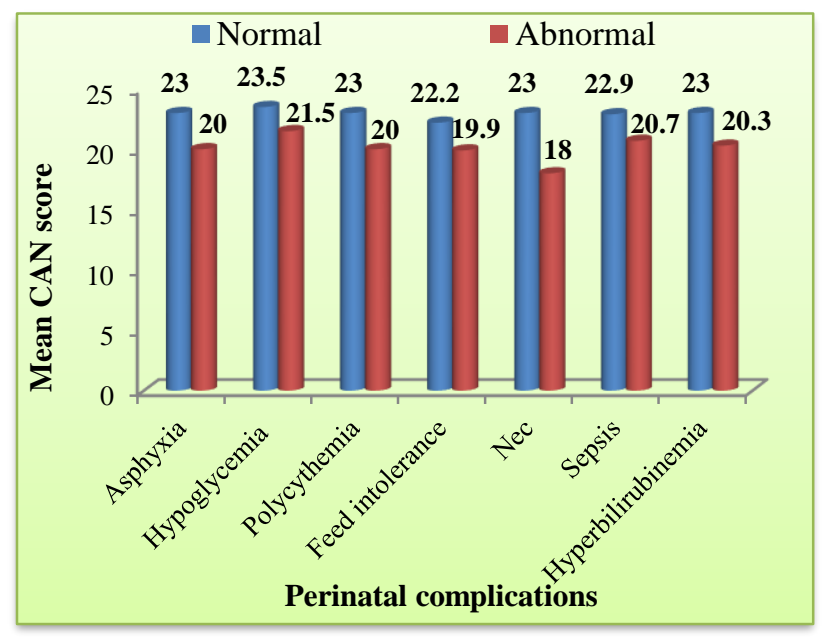

Figure 3: Association of CAN score with perinatal complications in both groups.

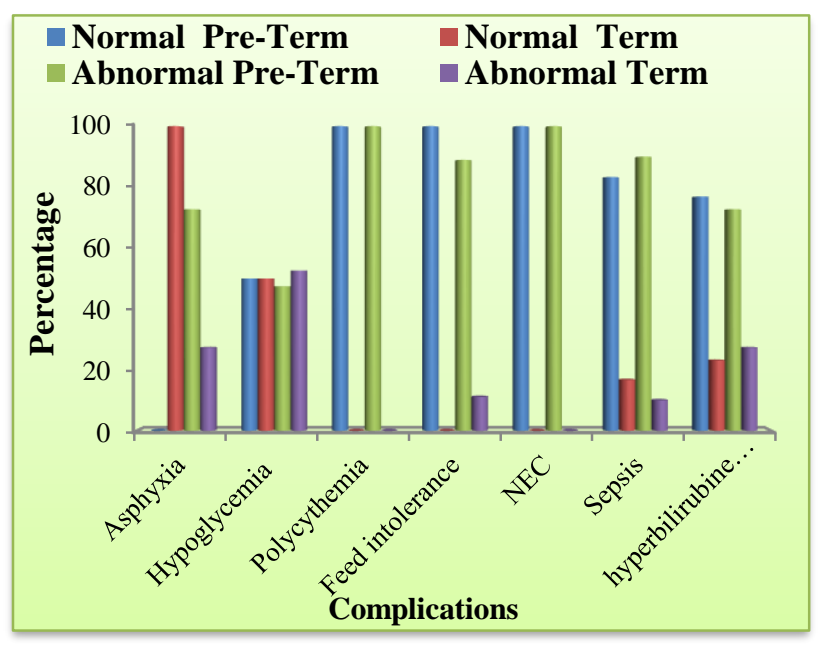

Figure 4: Comparison of perinatal complications in preterm and term IUGR infants in both groups.

Out of 60 IUGR infants, total 12 infants had perinatal asphyxia among which 11 were from case group and remaining 1 was from control group. Out of 11 infants in case group 8 were born preterm ( $<37$ completed gestation weeks) and 3 were born at term while in control group no preterm infant had asphyxia. Association of prematurity with perinatal asphyxia was not statistically significant.

\section{DISCUSSION}

It is important to recognize babies with growth restriction because of high incidence of neonatal morbidity and long term sequelae like metabolic syndrome. ${ }^{14-18}$ Depending on the period of gestation, when the malnutrition started, the clinical manifestations of growth restriction vary. Fetal malnutrition (FM) adversely affects body composition, including reduced muscle mass and protein content, organ structure and composition, bone, chemical composition and metabolic, and enzyme functions. ${ }^{19-22}$
In utero growth restriction is not a uniform condition with respect to its severity and duration, the underlying pathogenesis and the developmental stage of the fetus at the time of its occurrence. If malnutrition happens early in the second trimester, length, head circumference and weight are significantly reduced, whereas if length and head circumference are less affected but baby is small and underweight mostly the malnutrition happened in the beginning of the third trimester. If length and head circumference are within the normal range, and weight significantly less than the gestation age, an insufficient or unbalanced nutrient supply most likely occurred in the late third trimester.

CVS Lakshmi et al found that moderately preterm infants with a history of fetal growth restriction or exposure to preeclampsia, demonstration of antenatal absent or reversed end diastolic flow in the umbilical artery was shown to increase the risk for neonatal death. In our study IUGR infants with antenatal absent or reversed end diastolic flow were associated with increased perinatal complications but no mortality was observed. This study included only VLBW infants but our study includes IUGR infants with appropriate birth weight also. ${ }^{23}$

Deorari et al in their study on 144 SGA babies concluded that the most common morbidities were hypoglycemia $(17 \%)$ and polycythemia $(10 \%)$. In our study most common morbidity among IUGR infants was hypoglycemia (35\%) followed by sepsis (26.6\%). Feed intolerance, perinatal asphyxia, polycythemia and NEC were observed in $20 \%, 6.66 \%$ and $6.66 \%$ respectively. Our study includes detection of IUGR by umbilical artery Doppler antenatally compared to this study which doesn't. ${ }^{24}$ In a study perinatal complications of IUGR infants with absent and reversed diastolic flow was compared by Malhotra $\mathrm{N}$ et al according to them IUGR infants with reversed diastolic flow were associated with more morbidity and mortality. ${ }^{25}$ Similarly in our study also Infants with antenatal reversed umbilical artery Doppler flow were associated with more complications than absent flow but this association was not statistically significant. Mean duration of hospital stay was also more in infants with reverse flow compared to infants with absent flow.

\section{CONCLUSION}

Antenatal Doppler study of umbilical or middle cerebral artery blood flow is most useful in detection of IUGR antenatally. If detected antenatally by umbilical artery Doppler, infants with abnormal antenatal Doppler flow are at increased risk of perinatal complications than infants with normal antenatal umbilical artery Doppler and needs extra care during this period.

\section{Funding: No funding sources}

Conflict of interest: None declared

Ethical approval: The study was approved by the Institutional Ethics Committee 


\section{REFERENCES}

1. World Health Organization, WHO report: Reducing risks, promoting health life. Geneva, Switzerland, World Health Organization, 2002.

2. Battaglia FC, Lubchenco LO. A practical classification of newborn infants by weight and gestational age. J Pediatr. 1967;71:159-63.

3. Boulet SL, Alexander GR, Salihu HM, Kirby RS, Carlo WA. Fetal growth risk curve-Defining levels of fetal growth restriction by neonatal death risk. Am J Gynecol. 2006;195(6):1571-7.

4. Rosenberg A. The IUGR newborn. Perinatology. 2008;32:219-24.

5. Deonis M, Blossner M, Villar J. Levels and patterns of intrauterine growth retardation in developing countries. Eur J Clin Nutr. 1998;52:83-93.

6. United Nations childrens fund and World Health Organization, Low Birth weight: country, regional and global estimates. UNICEF, New York, USA. 2004.

7. Fanaroff AA, Hack M, Walsh MC. The NICHD neonatal research network: changes in practice and outcomes during the first 15 years. Semin Perinatol. 2003;27:281-7.

8. Cunningham FG, Williams JW, Williams. Obstetrics. McGraw-Hill. Medical Publishing Division, New York, USA. 2010.

9. Zhang J. Defining normal and abnormal fetal growth: promises and challenges. Am J Obstet Gynecol. 2009;10:889.

10. Mari G, Piconi J. Doppler vascular changes in IUGR. Perinatology. 2008;32(3):182-9.

11. Gonzalez JM, Stamilio DM, Ural S, Macones GA, Odibo AO. Relationship between abnormal fetal testing and adverse perinatal outcomes in intrauterine growth restriction. Am J Obst Gynecol. 2007;196(5):48-51.

12. Padmagirison R, Rai L. Fetal doppler versus NST as predictors of adverse perinatal outcome in severe preeclampsia and fetal growth restriction. J Obstet Gynecol. 2006;56:134-8.

13. Briana DD, Puchner AM. Intrauterine growth restriction and adult disease: the role of adipocytokines. European J Endocrinol. 2009;160(3):337-47.

14. Barker DJ, Gluckman PD, Godfrey KM, Harding JE, Owens JA, Robinson JS. Fetal nutrition andcardiovascular disease in adult life. 1993;41(8850):938-41.
15. lfirevic Z, Neilson JP. Biophysical profile for fetal assessment in high risk pregnancies. Cochrane Database Syst Rev. 2000;CD000038.

16. Katz J, Lee AC, Kozuki N, Lawn JE, Cousens S, Blencowe $\mathrm{H}$ et al. Mortality risk in preterm and smallfor gestational-age infants in low-income and middleincome countries: a pooled country analysis. Lancet. 2013;382:417-25.

17. Deorari AK, Agarwal R, Paul VK. Management of infants with intra-uterine growth restriction. Indian J Pediatr. 2008;75:171-4.

18. Dogra S, Mukhopadhyay K, Narang A. Feed intolerance and necrotizing enterocolitis in preterm small-for-gestational age neonates with normal umbilical artery Doppler flow. J Trop Pediatr. 2012;58:513-6.

19. Nezar MA, Baky AM, Soliman OA, Hady HA, Hammad AM, Haggar MS. Endothelin-1 and leptin as markers of intrauterine growth restriction. Indian $\mathbf{J}$ Pediatr. 2009;76:485-8.

20. Florio P, Marinoni E, Iorio R, Bashir M, Ciotti S, Sacchi R et al. Urinary S100B protein concentrations are increased in intrauterine growth retarded newborns. Pediatrics. 2006;118:747-54.

21. Sparks JW, Cetin I. Intrauterine growth and nutrition. In: Polin RA, Fox WW eds. Fetal and Neonatal Physiology, WB Saunders, Philadelphia, 1998.

22. Widdowson EM. Changes in body proportions and composition during growth. Scientific Foundations of Pediatrics. WB Saunders Co, Philadelphia, 1974;15563.

23. Lakshmi CV, Pramod G, Geeta K, Subramaniam S, Rao MB, Kallapur S, et al. Outcome of very low birth weight infants with abnormal antenatal Doppler flow pattern. Indian Pediatr. 2013;50:847-52.

24. Deorai AK, Agarwal R, Paul VK. Anagement of infants with intrauterine growth restriction. Indian $\mathrm{J}$ Pediatr. 2008;75:171-4.

25. Malhotra N, Chanana C, Kumar S, Roy K, Sharma JB. Comparison of perinatal outcome of growth-restricted fetuses with normal and abnormal umbilical artery Doppler waveforms. Indian J Med Sci. 2006;60(8):311-7.

Cite this article as: Shivaprasad B, Sharma D. To compare the perinatal outcome of IUGR infants with abnormal and normal antenatal umbilical artery doppler flow in the immediate neonatal period. Int J Reprod Contracept Obstet Gynecol 2017;6:1449-54. 